\title{
Interpretasi Fault Dan Horizon pada Reservoar Berdasarkan Penampang Seismik 2D dan Structure Map di Lapangan "T" Cekungan Jawa Timur Utara
}

\author{
Evan Hadyan Thirafi ${ }^{\text {a) }}$ dan Y. Yatini \\ Jurusan Teknik Geofisika, Fakultas Teknologi Mineral, Universitas Pembangunan Nasional "Veteran" \\ Yogyakarta. \\ a)email korespondensi : thirafievan@gmail.com
}

\begin{abstract}
ABSTRAK
Negara Indonesia merupakan salah satu negara dengan pengahasil minyak bumi dan gas alam terbesar di dunia. Salah satu cekungan yang terbukti menghasilkan minyak dan gas bumi yaitu Cekungan Jawa Timur Utara, dimana formasi yang dianggap zona reservoar merupakan formasi " $Z$ " dengan litologi berupa batugamping Globigerina. Zona reservoar terdapat struktur yang menghasilkan jebakan gas pada lapangan " $T$ " dimana penelitian ini bertujuan untuk mengetahui jenis trap dan arah penyebaran trap pada reservoar. Pada penelitian, dibutuhkan 3 data yaitu data seismik, data logging dan data marker. Data tersebut digunakan dalam picking horizon \& picking fault pada top formasi dan hasilnya berupa time structure map dan depth structure map. Pada penampang seimik lintasan B - B' berarah Utara - Selatan terdapat salah satu pola amplitudo khas yaitu wavy pararell dimana pola amplitudonya terlipat yang diinterpretasikan terjadi pada masa postdepositional tectonic. Seismic Section lintasan B - B' lebih banyak struktur dibandingkan lintasan A - A' sehingga penyebaran zona reservoar gas dan jebakan lebih banyak pada arah Utara - Selatan $(\mathrm{N}-\mathrm{S})$, hal ini ditandai dengan pola closure pada peta struktur waktu dan peta struktur kedalaman yang diinterpretasikan sebagai antiklin.
\end{abstract}

Kata Kunci : antiklin; interpretasi seismik; peta struktur.

\begin{abstract}
The country of Indonesia is one of the largest producers of petroleum and natural gas in the world. One of basins proven to produce oil and gas in the North East Java Basin, where formations considered as reservoir zone is "Z" formations with lithology of Globigerina Limestone. In the reservoir zone, there is a structure that produce a gas trap in the " $T$ " field where the aims are to determine the type of trap and the direction of trap in reservoair. In this research, there are three data, namely seismic data, logging data and marker data. The data used in picking horizon and picking fault on top formations and the results of these are time structure map and depth structure map. In the cross - section of the North - South direction of the B-B' line, there is one typical amplitude pattern, namely wavy parallel where the pattern folding and interpreted occur during the post tectonic period. Seismic Section B-B' has more structure than $A-A$ ' so that the distribution of gas reservoir zone and trap are in the North - South direction $(N-S)$, indicating a closure on time structure map and depth structure map that interpret as anticline.
\end{abstract}

Keyword : anticline; seismic interpretatio; structure map.

\section{PENDAHULUAN}

Negara Indonesia merupakan salah satu negara penghasil minyak dan gas bumi terbesar di dunia dan Negara Indonesia memiliki potensi sumber daya alam yang melimpah Sampai saat ini, energi minyak dan gas bumi masih menjadi kebutuhan primer di Negara Indonesia (Sihotang dkk, 2013). Pemerintah harus mampu memenuhi kebutuhan rakyat Indonesia terutama pada energi minyak dan gas bumi agar tidak terjadi kekurangan atau kelangkaan bahan bakar. Untuk memenuhi kebutuhan energi minyak dan gas bumi diperlukan kegiatan eksplorasi minyak dan gas bumi maupun pengembangan lapangan- lapangan minyak dan gas bumi agar produksi migas meningkat dari tahun ke tahun.

Pada kegiatan eksplorasi migas diperlukan metode geofisika yang dapat mendeteksi sifat - sifat batuan dan fluida dibawah permukaan bumi. Salah satu metode yang digunakan untuk kegiatan eksplorasi minyak dan gas bumi yaitu metode seismik refleksi. Seismik refleksi merupakan salah satu metode geofisika yang bersifat aktif yang aplikasinya dapat digunakan untuk eksplorasi minyak dan gas bumi, mendeteksi struktur lapisan, stratigrafi bawah permukaan, serta litologinya (Sukmono, 1999).

Salah satu cekungan yang berpotensi menghasilkan minyak dan gas bumi yaitu Cekungan Jawa Timur Utara (Triyana dkk, 2007). Cekungan Jawa Timur Utara dibatasi oleh busur karimunjawa yang memisahkanya dengan 
cekungan jawa barat utara, sebelah timur dibatasi oleh Cekungan Lombok, sebelah selatan dibatasi oleh Busur Vulkanik dan sebelah utara dibatasi oleh suatu tinggian yang memisahkanya dengan Selat Makassar (Mudjiono dan Pireno, 2002). Pada Cekungan Jawa Timur Utara, salah satu daerah yang berpotensi menghasilkan minyak dan gas bumi yaitu Madura Strait, dimana formasi yang berpotensi menghasilkan gas yaitu formasi "Z" yang berlitologi batugamping globigerina yang berporositas tinggi dan sangat baik dijadikan sebagai zona reservoar gas pada lingkungan moderately deep water (Triyana dkk, 2007).

Tujuan dari penelitian ini yaitu mengetahui jenis dan arah penyebaran trap pada zona reservoar berdasarkan seismic section dan structure map menggunakan metode seismik refleksi.

\subsection{Geologi Regional Cekungan Jawa Timur Utara}

Cekungan Laut Jawa Bagian Timur terletak di bagian ujung selatan Craton Sunda dan memiliki luas sekitar $50.000 \mathrm{~km}^{2}$. Cekungan berumur Eosen ini terbentuk sebagai cekungan busur belakang (back arc basin) yang berasosiasi dengan busur volkanik di selatan (Mudjiono dan Pireno, 2002) yang ditunjukan pada gambar 1. Pada Zaman Kapur Akhir cekungan ini merupakan cekungan laut di bagian selatan zona subduksi (Satyana dan Purwaningsih, 2003). Cekungan Laut Jawa Bagian Timur dibatasi di bagian barat oleh Karimunjawa Arch, di bagian timur oleh lingkungan laut dalam Lombok, Flores, Salayar dan Cekungan Makasar Selatan. Cekungan ini memanjang ke arah timur-laut dari lepas pantai busur volkanik Laut Jawa hingga ujung tenggara Kalimantan dan bergabung dengan bagian selatan Selat Makasar dan dibatasi di bagian timur-laut oleh Paternoster Platform dan Zona Sesar Adang. Batuan dasar Cekungan Laut Jawa Bagian Timur tersegmentasi menjadi beberapa bentukan horst dan graben yang memiliki arah NE - SW (Satyana dan Purwaningsih, 2003). Peta cekungan Jawa Timur dapat dilihat pada Gambar 1 dibawah ini.

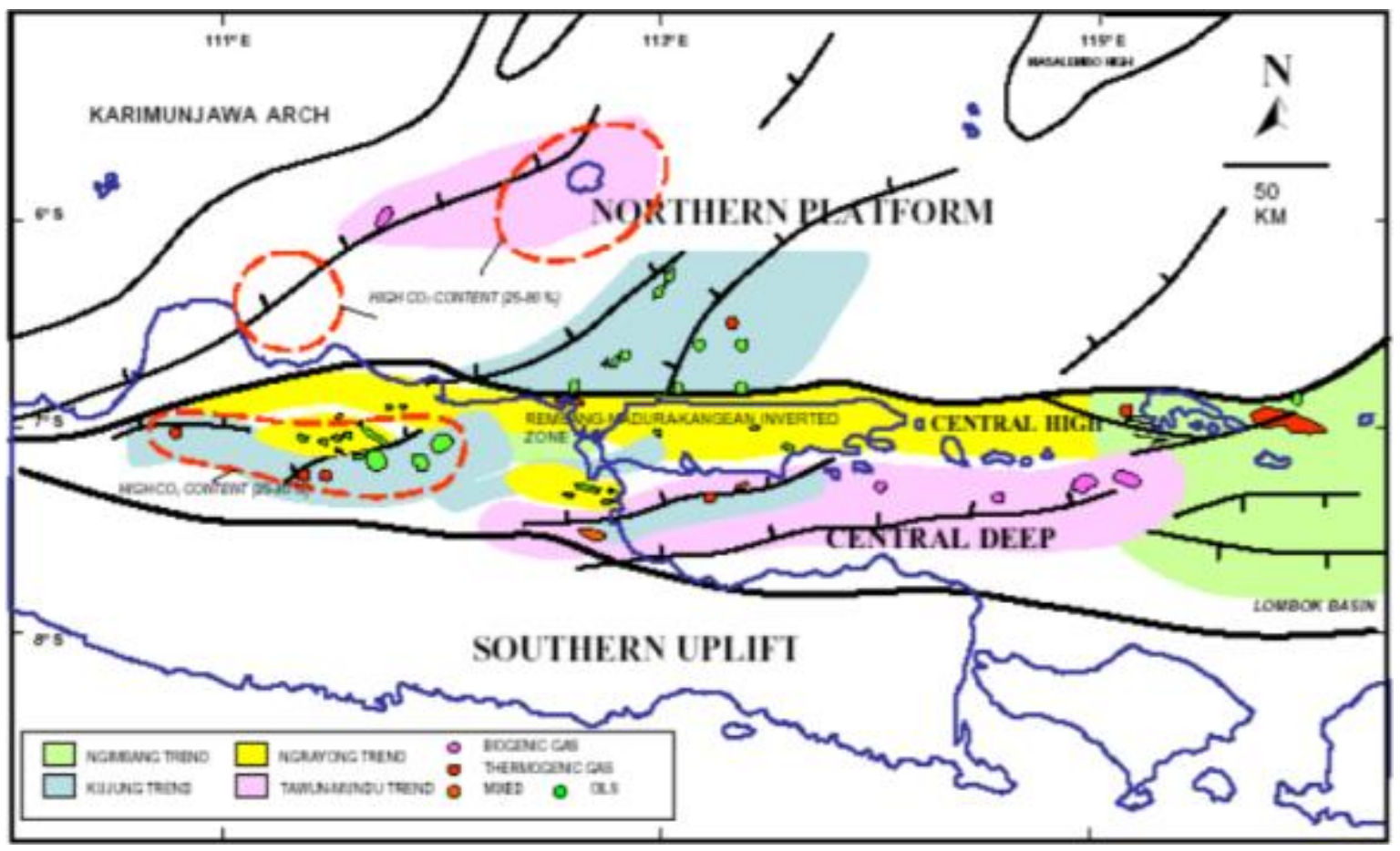

Gambar 1. Peta Cekungan Jawa Timur Utara (Satyana dan Purwaningsih, 2003)

\subsection{Stratigrafi Cekungan Jawa Timur Utara}

Menurut Mudjiono dan Pireno (2002), Batuan dasar terdiri dari berbagai macam intrusi dan ekstrusi dari batuan beku, termasuk diantaranya gabro, basal andesitik, dan tufa metamorfik dan beberapa sedimen Pra-Tersier yang belum termalihkan. Litologi dari batuan dasar diperkirakan berumur Kapur dengan sampel basal yang menghasilkan usia 64,58 juta tahun yang lalu yang ditunjukan pada gambar 2. Adapun formasi - formasi pada Cekungan Jawa Timur Utara sebagai berikut : 


\section{a. Formasi Ngimbang}

Formasi Ngimbang dapat dibagi menjadi 4 (empat) anggota (terurut dari tua ke muda) yaitu : Anggota Pra "CD", Anggota "CD", Anggota Ngimbang Clastic / NGC dan Anggota Ngimbang Limestone / Lower Limestone / LLNG. Anggota Pra "CD" terdiri dari batugamping, serpih ,batupasir, batulempung, batulanau, dan konglomerat dengan sedikit lapisan tipis batubara. Ketebalan anggota ini pada umumnya tipis dan menebal ke daerah rendahan. Umur dari sedimen Anggota Pra "CD" sedimen diasumsikan berumur Eosen (Mudjiono dan Pireno, 2002). Anggota "CD" sebagian besar terdiri dari batugamping dengan perselingan serpih dan batupasir dan secara lokal terdapat sedimen tufaan. Pengendapan dari sedimen Anggota "CD" sebagian besar dikontrol oleh topografi batuan dasar. Anggota Ngimbang Clastic / NGC diendapkan tidak selaras diatas Anggota "CD". Anggota Ngimbang Clastic / NGC terdiri dari serpih, batugamping, batupasir dan batulempung. Serpih biasanya terdapat pada bagian paleo-lows sedangkan pada bagian paleo-highs sedimentasi platform karbonat (Reef). Secara umum, pengendapan terjadi selama fase regresif. Anggota Lower Limestone / LL terdiri dari batugamping dan perselingan dengan batuserpih. Secara regional, anggota ini diendapkan berumur Oligosen Awal hingga Oligosen Tengah (Mudjiono dan Pireno, 2002).

\section{b. Formasi Kujung}

Formasi Kujung dapat dibagi menjadi dua unit (terurut dari tua ke muda), Kujung II dan Kujung I. Kujung II secara selaras diendapkan diatas Formasi Ngimbang dengaan litologi oleh Batuserpih dan Batugamping dengan sedikit kehadiran batupasir dan batulanau. Patch reefs menjadi fitur yang umum terjadi pada waktu pengendapan Kujung II dan beberapa fragmen koral, alga, dan sedimen longsoran yang terdapat di dalam matriks mikritik. Sikuen ini diendapkan pada waktu kondisi transgresi. Diendapkan Formasi Kujung I secara selaras pada kala Miosen Awal (Mudjiono dan Pireno, 2002). dengan litologi batugamping masif dimana variasi ketebalan sangat dimungkinkan sebagai akibat adanya pembentukan terumbu secara lokal. Batugamping pada umumnya berwarna putih sampai agak putih, mengandung banyak fosil, chalky dan dolomit di beberapa bagian.

\section{c. Formasi "OK"}

Formasi "OK" dapat dibagi menjadi dua anggota, yaitu Anggota Lower "OK" dan Anggota Upper "OK". Anggota Lower "OK" dapat dibagi menjadi dua unit yaitu, unit karbonan bagian bawah, Rancak, dan unit klastik bagian atas. Unit Rancak terdiri dari batugamping, serpih, dengan beberapa batupasir, batulanau dan perselingan batulempung. Anggota Upper "OK" dicirikan oleh sekuen batugamping yang tebal dan masif dengan sisipan batupasir dan batulempung. Kearah cekungan, terdapat perubahan menjadi perlapisan yang lebih tipis, fasies karbonat berenergi rendah, diselingi dengan sedimen klastik yang halus.

\section{d. Formasi "GL-MT"}

Formasi "GL-MT" merupakan formasi yang berumur upper miocene - pliosen dan dapat dibagi menjadi dua anggota (terurut dari tua ke muda), Anggota "GL" dan Anggota "MT". Anggota "GL" terdiri dari batugamping, batulempung, batupasir, dan batulanau, sementara ke arah selatan sekuennya sebagian besar berupa batulempung dengan perselingan batupasir, batulanau dan napal. Batugamping terumbu tumbuh pada paleo-high tetapi berubah fasies menjadi lapisan tipis, fasies karbonat energi yang rendah dan sedimen klastik yang halus pada bagian paleo-low. Anggota MT memiliki litologi dengan bottom MT, yaitu batugamping dengan Claystone (Fining Upward) dengan sisipan sands dan skeletal. Anggota MT diendapkan pada umur upper Miocene dengan lingkungan shallow outer sublitoral. Stratigrafi cekungan Jawa Timur dapat dilihat pada Gambar 2 dibawah ini. 


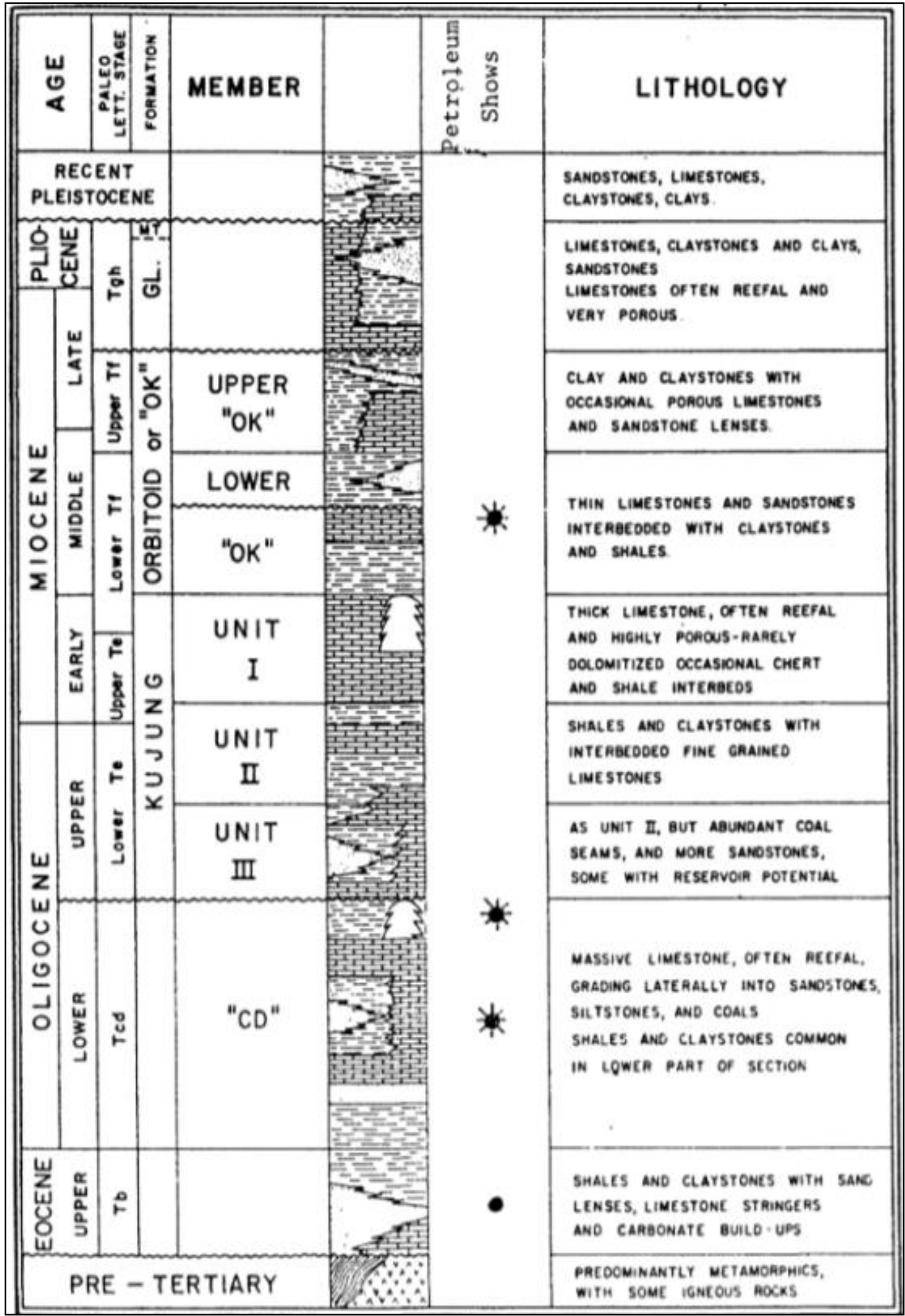

Gambar 2. Stratigrafi Cekungan Jawa Timur Utara (Kenyon, 1977 


\section{METODE}

Diagram alir penelitian "Interpretasi Fault dan Horizon pada Zona Reservoar Berdasarkan Penampang Seismik 2D dan Structure Map di Lapangan "T' Cekungan Jawa Timur” ditunjukan pada Gambar 3.

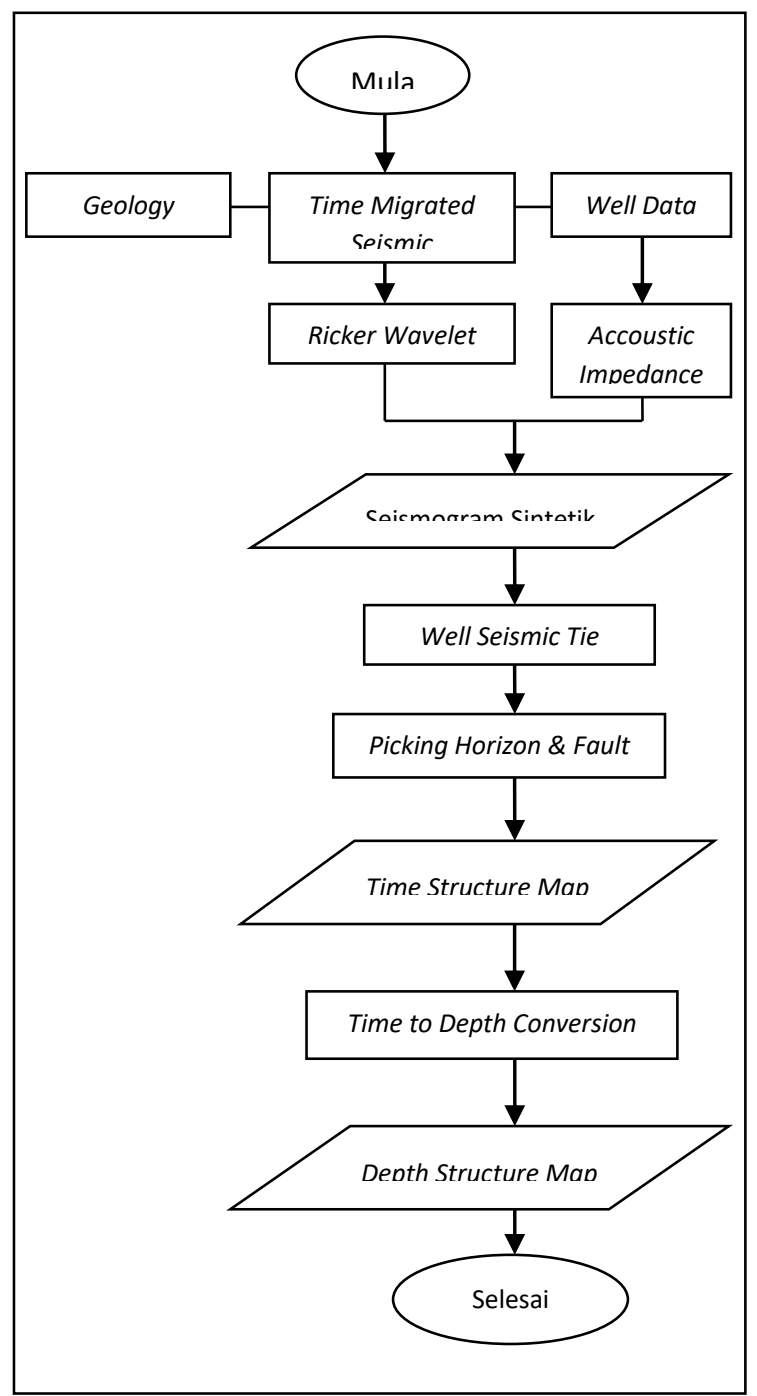

Gambar 3. Diagram alir penelitian interpretasi fault dan horizon pada penampang seismik 2D di Lapangan "T" Cekungan Jawa Timur Utara

Data yang dipergunakan dalam penelitian ini adalah data Seismik, data Sumur dan data Geologi. Data seismik (Time Migrated Seismic) dengan masing - masing data memiliki sampling rate 2 ms. Data sumur yang digunakan adalah data Well Logging, data Checkshot dan data Marker. Data Well Logging yang dibutuhkan yaitu data $\log$ density dan log P-Slowness yang digunakan untuk mencari nilai akustik impedansi dan koefisien refleksi. Data Checkshot digunakan untuk kepentingan Well to seismic tie. Dimana data checkshot berguna untuk merubah data sumur dari domain kedalaman ke domain waktu dan mengkoreksi pergeseran waktu yang didapat dari pengukuran seimik konvensional dengan pengukuran seismik dalam sumur. Data marker digunakan untuk kepentingan picking horizon pada top formasi "Z" pada lapangan "KK". Selain itu data marker digunakan untuk mengetahui kedalaman top formasi "Z" dan time to depth conversion untuk menghasilkan depth structure map. Data geologi berupa litologi dan struktur regional yang terdapat pada lapangan "KK" Cekungan Jawa Timur Utara, urutan stratigrafi dan juga lingkungan pengendapan masing - masing formasi. 


\subsection{Generate Wavelet Data Seismik}

Untuk membuat seismogram sintetik, terlebih dahulu dibuat wavelet sintetis Ricker Wavelet untuk kepentingan pengikatan data sumur ke data seismik (Well To Seismic Tie). Untuk menghindari dari noise pada data seismik, dibuatkan frekuensi dominant pada wavelet sintetik sebesar $25 \mathrm{~Hz}$. Gambar 4 menunjukkan contoh pembuatan wavelet sintetik. Langkah selanjutnya adalah well to seismic tie dengan mengikat data sumur ke data seismik.

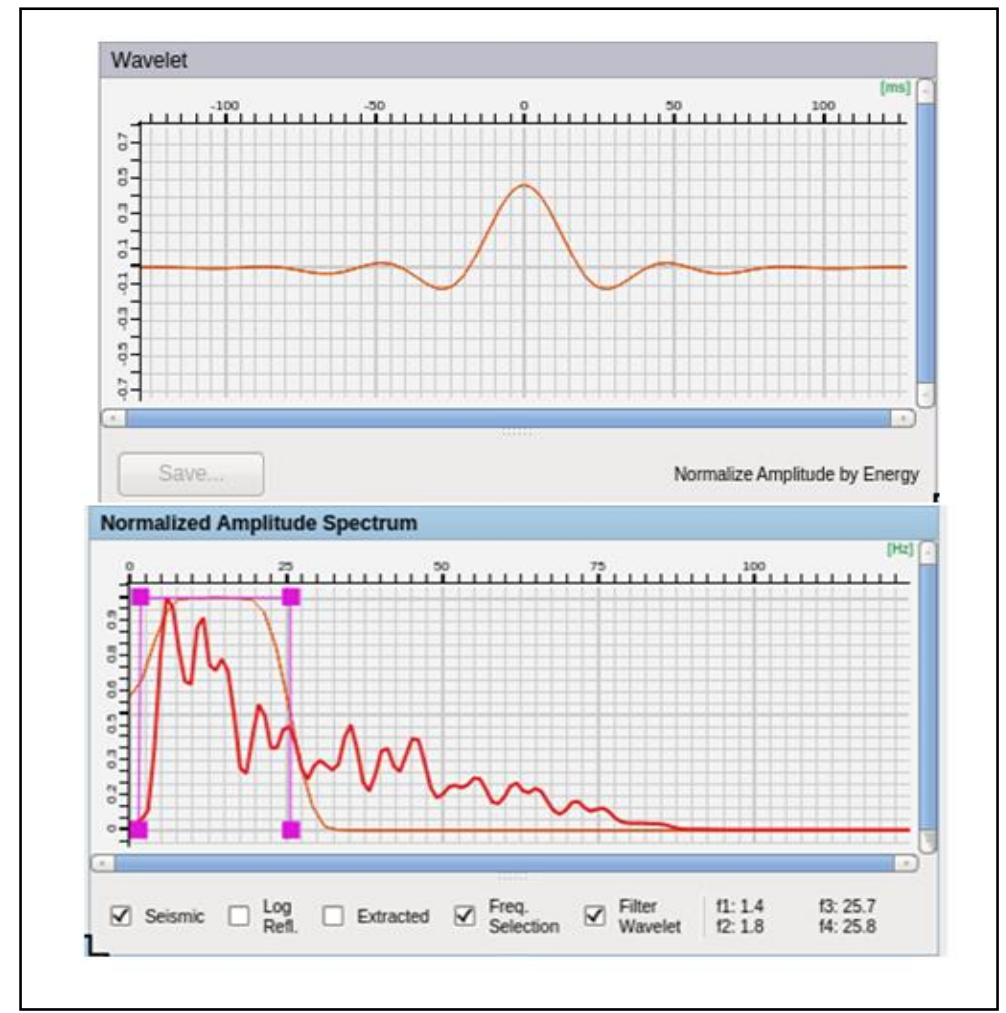

Gambar 4. Frequency Setting seismogram sintetik sumur "KK" Lapangan "T" Cekungan Jawa Timur Utara

\subsection{Picking Fault dan Picking Horizon}

Picking Fault dan Picking Horizon merupakan salah satu tahap interpretasi data seismik. Interpretasi dilakukan dengan mempertimbangkan konsep geologi seperti struktur geologi, kemenrusan lapisan Sedangkan interpretasi seismik seperti kemenerusan amplitudo gelombang, low and high amplitude, polaritas seismik dll. Untuk melakukan picking horizon harus dibantu dengan top marker data sumur, setelah itu dilakukanlah picking horizon dengan melihat kemenerusan amplitudo. Tahap selanjutnya yaitu picking fault dengan menandai adanya sesar.

\subsection{Time structure Map}

Merupakan peta struktur waktu yang memiliki domain time yang menunjukan geometri struktur pada bawah permukaan. Input data untuk membuat time structure map yaitu hasil dari picking horizon dari map boundary. Dalam pembuatan peta struktur waktu, terdapat beberapa metode gridding dimana, pemilihan metode gridding harus diperhatikan dengan benar agar peta tersebut dapat mempresentasikan morfologi / geometri bawah permukaan.

\subsection{Time to Depth Conversion}

Merupakan peta struktur yang memiliki domain kedalaman yang menunjukan geometri bawah permukaan. Input data untuk membuat peta struktur kedalaman yaitu hasil dari peta struktur waktu yang dimasukan kedalam suatu algoritma. Algoritma tersebut dibuat dengan mencari hubungan antara data TWT Checkshot dengan TVDSS Checkshot pada sumur "KK" lapangan "T". Gambar 5 menunjukkan kurva yang menggambarkan hubungan TVDSS dan TWT pada Lapangan "T" sumur "KK". 


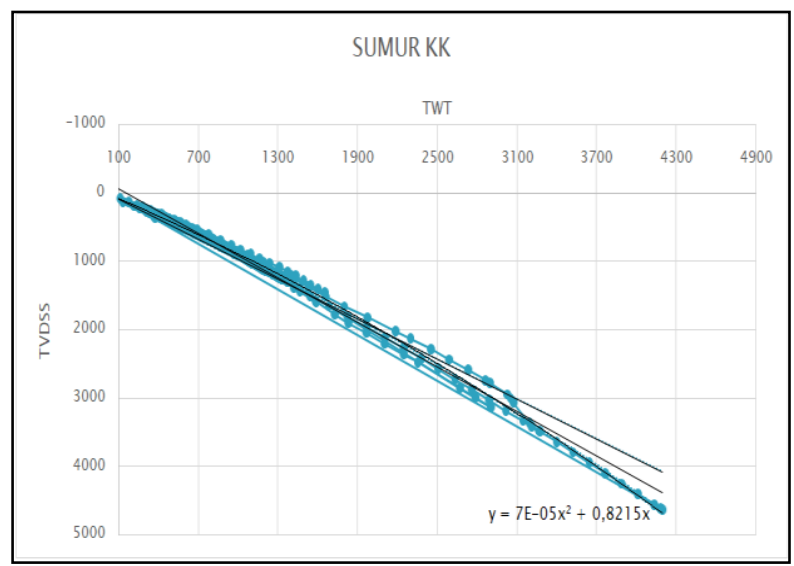

Gambar 5. Kurva TWT vs TVDSS Sumur "KK” Lapangan "T" Cekungan Jawa Timur Utara

\section{HASIL DAN PEMBAHASAN}

Pada Basemap terdapat 2 line yang memotong sumur yaitu line $\mathrm{A}-\mathrm{A}^{\prime}$ dan line $\mathrm{B}-\mathrm{B}$ ' dimana line yang diinterpretasi line B - B'. Hal ini dikarenakan struktu yang kompleks yang ditunjukan pada Gambar 6.

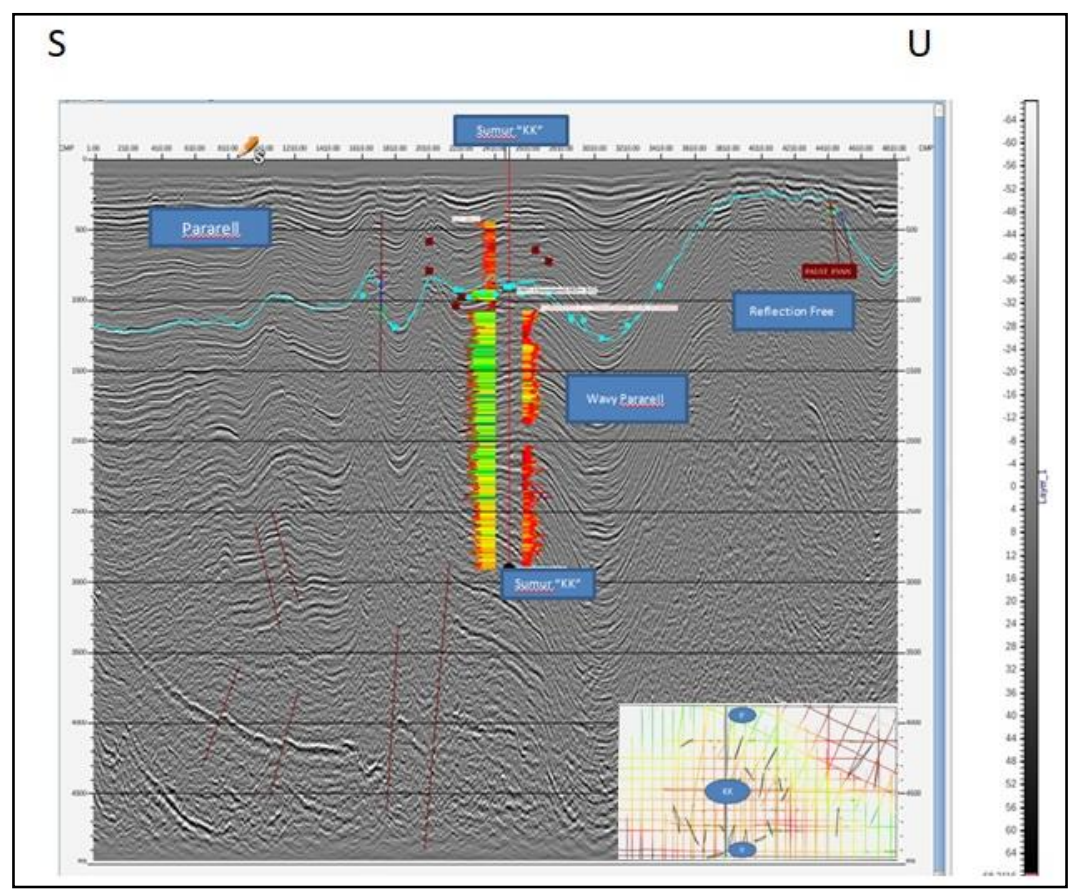

Gambar 6. Seismic Section Line B - B' Sumur “KK”, Lapangan T, Cekungan Jawa Timur Utara.

Top formasi $\mathrm{Z}$ yang diinterpretasi sebagai reservoar gas dengan ketebalan gas pada sumur sebesar 20 meter. Pada penampang tersebut terdapat log Gamma Ray dan log P- Velocity. Pada log Gamma ray, formasi Z memiliki kisaran nilai 77.052 API sampai 43.813 API pada kedalaman 810.9 meter - 822.2 meter. Pada PVelocity baru mengukur pada kedalaman 978 meter, sehingga tidak mengukur velocity pada formasi Z.

Pada penampang dengan llintasan B - B', terdapat karakteristik amplitudo yaitu Wavy Parararell, reflection free dan sub pararell. Pada Wavy Pararell, ampitudo membentuk seperti lipatan dengan karakteristik amplitudo yang menerus dan rapat. Diinterpretasikan wavy pararell terbentuk akibat proses tektonik postdepositional setting, sehingga mengakibatkan terbentuknya lipatan. Lipatan ini digunakan sebagai trap pada zona reservoar batugamping sehingga akumulasi gas dapat terjebak. Selain itu terdapat pola Reflection free dibagian sebelah utara yang ditandai pola amplitudo yang hilang. Diinterpretasikan pola tersebut terjadi karena kontras AI yang sangat kecil yang kemungkinan endapan klastika halus lebih tebal,sehingga amplitudo tidak terlalu terlihat, Selanjutnya terdapat pola subpararell pada penampang bagian selatan, hal ini ditandai dengan amplitudo yang tidak terlalu pararell dan kemenerusanya masih terlihat. Pada penampang dengan lintasan B - B, dibagian utara 
menghasilkan pola reflection free yang diinterpretasikan endapan klastika halus dapat lebih tebal, sedangkan pada bagian selatan penampang diinterpretasikan endapan kalstika kasar lebih tebal.

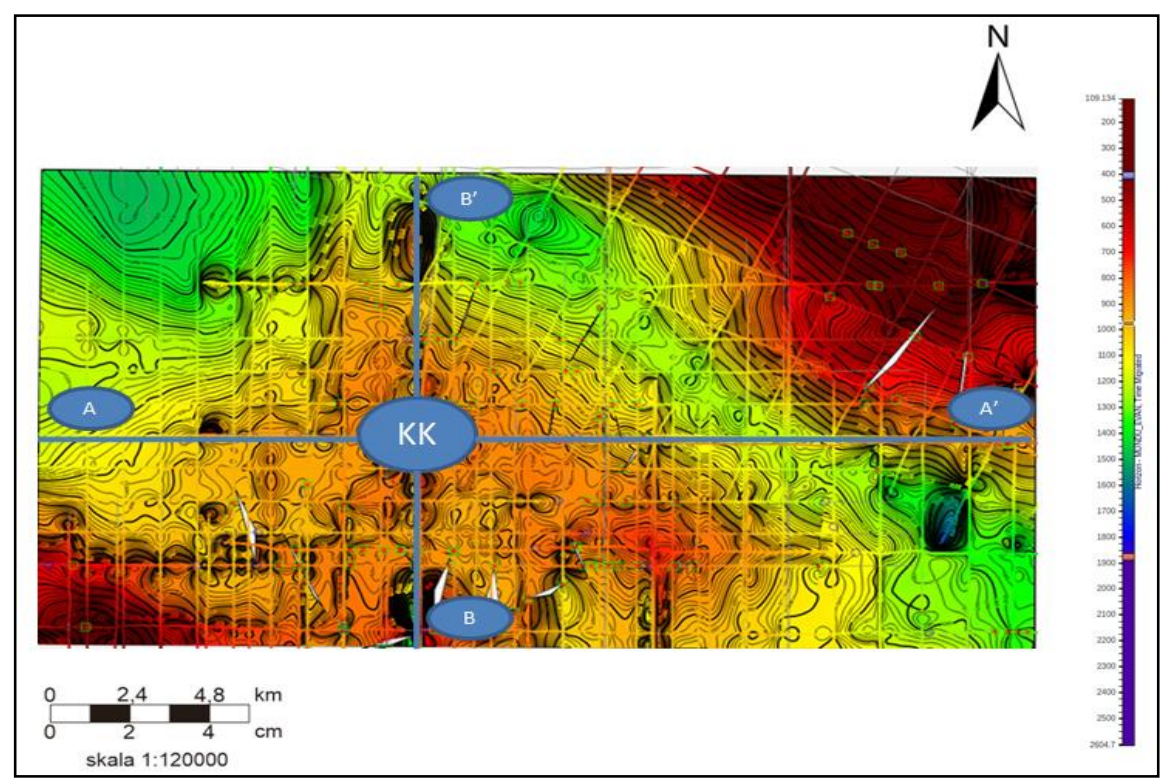

Gambar 7. Time Structure Map Sumur "KK" Lapangan "T” Cekungan Jawa Timur Utara

Time structure map merupakan peta kontur yang mempresentasikan suatu lapisan dibawah permukaan yang memiliki kedalaman dalam domain waktu (ms) yang ditunjukan pada Gambar 7. Peta ini dibuat berdasarkan hasil picking horizon pada top formasi "Z" dengan skala 1:120000 dengan metode gridding minimum curvature dan interval kontur sebesar $20 \mathrm{~ms}$ dengan skala nilai sebesar $109.134 \mathrm{~ms}$ - $2604.7 \mathrm{~ms}$. Peta ini dibuat beradasarkan top formasi "Z" dimana formasi tersebut merupakan reservoar gas berlitologi batugamping.

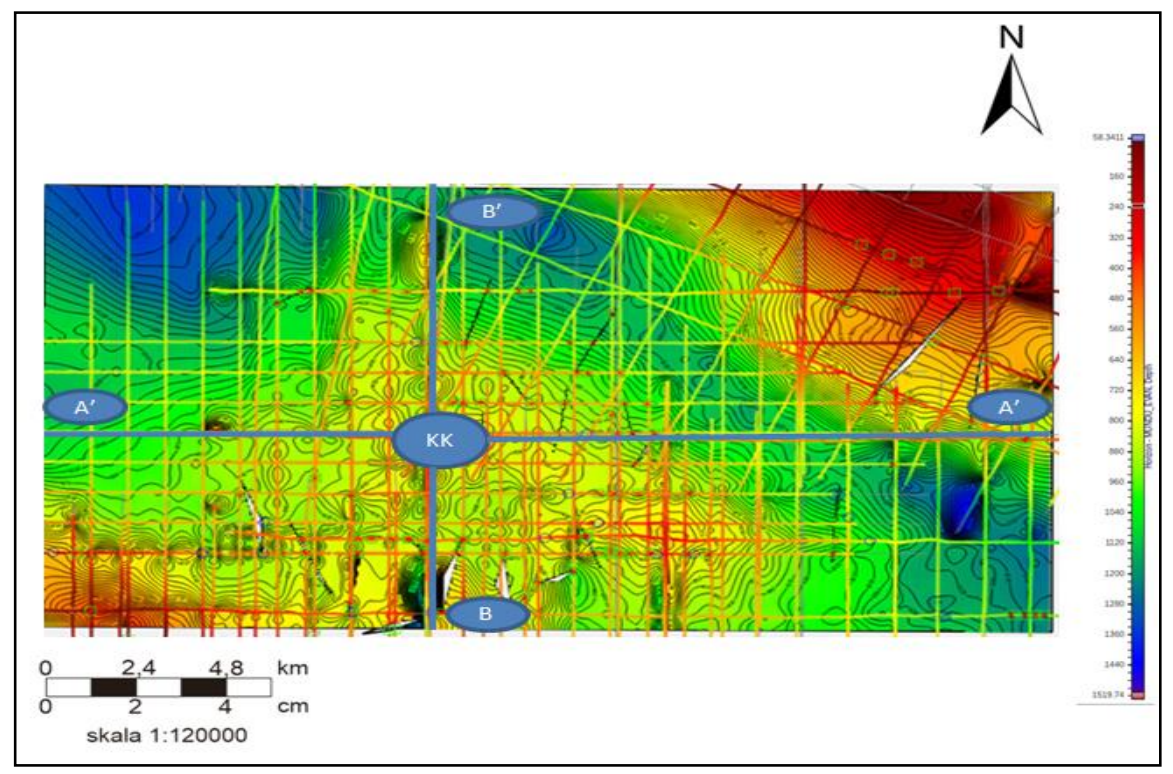

Gambar 8. Depth Structure Map Sumur "KK" lapangan "T" Cekungan Jawa Timur Utara

Pada peta diatas, elevasi berdasarkan domain time pada sumur "KK" sebesar $900 \mathrm{~ms}$, dimana pada disekitar area sumur, telihat top formasi "Z" membentuk closure yang diinterpretasikan sebagai zona antiklin, dimana zona tersebut sangat cocok untuk trap agar akumulasi terjebak. Pada Time Structure Map berdasarkan Top Formasi "Z" jarang dijumpai struktur berupa sesar karena kemenerusan amplitudo masih terlihat jelas, yang terlihat hanya lipatan berupa antiklin. Pembuatan time structure map berasal dari pengukuran seismik konvensional, dimana kemungkinan masih terdapat beberapa noise, maka dari itu harus dikonversikan kedalam depth structure map

Depth Structure Map merupakan peta kontur dengan domain kedalaman yang dibuat dengan mengkonversi dari waktu ke kedalaman menggunakan time to depth conversion yang ditunjukan pada Gambar 8. Persamaan yang 
digunakan untuk membuat depth structure map yaitu persamaan polynomial dengan $\mathrm{y}=7 \mathrm{E}-05 \mathrm{x}^{2}+0,8215 \mathrm{x}$. Peta ini dibuat beradasarkan top formasi "Z" dimana formasi tersebut merupakan zona reservoar.

Pada time structure map, kedalaman top formasi bernilai $700 \mathrm{~ms}$ dimana diinterpretasikan dengan kedalaman dangkal, sedangkan pada depth structure map kedalaman top formasi bernilai 860 meter dimana berdasarkan kedalaman dari data sumur, nilai kedalaman top formasi $\mathrm{Z}$ sebesar 860 meter. Pada depth structure map dengan rentang nilai kedalaman 100.178 meter - 1484.39 meter ini terdapat bentuk closure yang menandakan adanya suatu lipatan yang dinterpretasikan sebagai akumulasi keberadaan gas yang berada pada lintasan sumur "KK". Selain itu pada lintasan yang berarah barat - timur relatif tidak memiliki struktur terutama pada daerah formasi "Z" sedangkan pada lintasan utara selatan relatif memiliki banyak struktur berupa lipatan.

\section{KESIMPULAN}

Seismic section lintasan Utara - Selatan (N-S) lebih banyak terdapat struktur dibandingkan lintasan Barat - Timur (W-E). Trap lebih banyak tersebar di Utara - Selatan $(\mathrm{N}-\mathrm{S})$, sehingga penyebaran zona reservoar lebih banyak di daerah dengan arah Utara - Selatan $(\mathrm{N}-\mathrm{S})$. Pada time structure map dan depth structure map terlihat ada pola closure yang diinterpretasikan sebagai antiklin.

\section{UCAPAN TERIMAKASIH}

Penulis mengucapkan rasa terimakasih kepada Bapak Syaeful Amin selaku pembimbing penelitian diperusahaan dan Bapak Arief Prakosa yang telah memberikan kesempatan kepada penulis untuk mengerjakan penelitian ini.

\section{DAFTAR PUSTAKA}

Kenyon, C. S. (1997). Distribution and morphology of early miocene reefs, East Java Sea, Indonesian Petroleum Association $6^{\text {th }}$ Annual Convention.

Mudjiono, R. \& Pireno, G.E.. (2002). Exploration of the North Madura Platform, Offshore East Java, Indonesia. In Proceedings Indonesian Petroleum Association, Twenty-eighth Annual Convention \& Exhibition, October 2001.

Satyana dan Pu8rwaningsih. (2003). Oligocene carbonate of Java : tectonic setting and effect of volcanism. Proceedings of Joint Convention IAGI \& HAGI

Sukmono, S. (1999). Interpretasi Seismik Refleksi. Teknik Geofisika. Bandung: ITB.

Triyana, Y., Harris, I. G., Basden, A. W., Tadiar, E., Sharp, C. N. (2007). The Maleo Field : An example of the pliocene globigerina bioclastik limestone play in the East Java Basin - Indonesia. Proceedings Indonesian Petroleum Association. Thirty - First Annual Convention \& Exhibition. 